\title{
Comprender el saber docente desde la metodología de las historias de vida
}

\author{
Rosario García-Huidobro Munita. Universidad de Barcelona
}

Recepción: 12 de abril de 2015 | Revisión: 30 de mayo de 2015 | Aceptación/Publicación: 24 de julio de 2015

Correspondencia: rosarioghm@gmail.com | http://hdl.handle.net/10481/37130

\begin{abstract}
Resumen: Este escrito se centra en los aspectos metodológicos que conllevó explorar, desde la perspectiva de las historias de vida, cómo cuatro profesoras de artes visuales de secundaria conforman su saber docente. Para ello, se pone en el centro las características más significativas de esta metodología -la subjetividad, el vínculo investigadorinvestigado, la reflexividad y su potencial transformador-como aspectos que, en este estudio, fueron considerados y desarrollados de manera primordial, ya que permitieron evidenciar cómo las mujeres no están determinadas simplemente por los discursos dominantes e históricos sobre el género, sino que pueden ser agentes activas en negociar estos discursos, deseos y sentidos de ser en el mundo, a partir de relatarse a sí misma.
\end{abstract}

Palabras claves: Historias de vida | Narrativas personales | Saber docente | Mujeres

UNDERSTANDING THE TEACHING METHODOLOGY KNOW FROM LIFE STORIES

Abstract: This paper focuses on the methodological aspects which led to explore, from the perspective of the life histories, how four teachers of visual arts from secondary school, conform their teaching knowledge. For this, we put in the center the most significant characteristics of this methodology -the subjectivity, the researcher-researched relationship, reflexivity and its potential of change- like aspects which, in this study, were considered and developed primarily, because allowed to evidence how women are not simply determined by the dominant and historical discourses of gender, but may be active agents in negotiating these discourses, desires and ways of being in the world, from recounting themself.

Keywords: Life Histories | Personal Narratives | Teacher Knowledge | Women

Agradecimiento: Comisión Nacional de Investigación Científica y Tecnológica, CONICYT

\section{Introducción}

Este escrito surge de la investigación doctoral que desarrollo en la Universidad de Barcelona, en la cual busco comprender -a partir de la perspectiva de las historias de vida- cómo cuatro profesoras de artes visuales, de educación secundaria en Chile, conforman sus saberes docentes, desde sus sentidos de ser mujer y sus prácticas artísticas. La propuesta es evidenciar cómo han ido conformando sus saberes pedagógicos a través de los relatos y el análisis de sus diversas experiencias, tomando en cuenta que éstos están cargados de tensiones que, producto de los roles tradicionales femeninos y masculinos, complejizan sus experiencias cotidianas como mujeres, artistas y docentes.

A partir de este desafío, la metodología biográfica narrativa -para la reconstrucción de sus historias de vida- ha sido un aspecto crucial. Así también, el método utilizado para analizar los relatos y otras evidencias -la teoría fundamentada-tuvo un lugar importante, ya que ayudó a comprender las dimensiones que, como categorías, daban un nuevo sentido a sus saberes, y permitieron dar un orden simbólico al cómo serían reconstruidas sus historias, para visibilizar el problema de unos saberes que estaban muy próximos a sus experiencias como mujeres y artistas.

A partir de esta breve descripción sobre el estudio, en este escrito me centraré en los diversos aspectos y procesos metodológicos que desarrollé para reconstruir sus historias de vida. Para ello, en el próximo apartado explicaré cómo y por qué me acerqué a la narrativa, así también compartiré la importancia de esta metodología y 
cómo, las características más importantes de las historias de vida, fueron desarrolladas en mi relación con las colaboradoras y perspectiva de investigación.

\section{La metodología narrativa y su enfoque de investigación}

Me acerqué a la investigación narrativa cuando comencé a desarrollar el máster, "Artes Visuales y Educación: un enfoque Construccionista", el año 2011 en la Universidad de Barcelona. Estas instancias de encuentro me permitieron comprender que vivimos vidas relatadas y que, desde estas historias de experiencia, nos conformamos constante y mutuamente. Estos aspectos han sido cruciales para interesarme por este enfoque en mi vida personal, profesional y de investigación. A lo largo de este camino de aprendizaje, autores como Clandinin \& Connelly $(1990,1994$, 1995, 2000), Bruner (1990, 2004), Bolivar, (2002, 2006), entre otros, me han mostrado que investigar la experiencia desde este enfoque significa comprender a la narrativa como herramienta que nos ayuda a interpretar los significados de nuestras experiencias vividas, en y desde los relatos. Desde este interés por la narrativa, como herramienta que permite relatarnos, pienso que todos tenemos muchas historias que contar. Como seres humanos, somos seres historiados y nos conformamos desde los relatos de experiencia que construimos y contamos sobre nuestra vida (Clandinin \& Connelly, 1990, 1995, 2000).

Desde este interés por la narrativa, como método para conocernos, opté —en mi estudio- comprender el problema del saber docente desde la perspectiva de las historias de vida. Decidí acercarme a comprender las vivencias y relatos de cuatro mujeres artistas y docentes, lo cual y a su vez, implicó conocer el enfoque fenomenológico y comprender sus vínculos con la experiencia como fenómeno de estudio. Ambos enfoques, no sólo tienen en común que problematizan la noción de experiencia, sino que también el proceso de contar, relatar o narrarlas son situaciones de interés para ambos. Aun así, si bien la fenomenología se basa en la experiencia vivida como noción clave de estudio (Van Manen, 2003), la investigación biográfica narrativa también comienza en la experiencia, pero desde la expresión de historias vividas y contadas.

Para ello, en un período de seis meses, realicé siete entrevistas con cada participante, en las que, a partir de diversos temas y preguntas semiestructuradas, me relataron diversos aspectos de sus vidas. Así también realizamos dos focus group con todo el grupo y las acompañé, durante ese período, a sus prácticas docentes, en los cuales observaba cómo se relacionaban con sus diversos saberes y cómo los compartían con sus estudiantes.

Acercarme a conocer en profundidad las historias de estas mujeres y cómo las diversas experiencias sociales, políticas y personales las llevaban a comprender y enfrentar sus prácticas artísticas y docentes, nos permitió ir comprendiendo, en conjunto, de qué manera lo individual -como personal- dialogaba con lo social, y ponía en juego la conformación de sus saberes y subjetividades como mujeres.

Si bien para el análisis de las evidencias utilicé herramientas de la teoría fundamentada, como la codificación abierta, axial, selectiva, memos, entre otros elementos, la perspectiva narrativa ha sido el hilo que ha permitido relacionar y visibilizar sus relatos de experiencia como formas de subjetividad. El uso de la teoría fundamentada (Charmaz, 2006; Bryant y Charmaz, 2007) ayudó, no sólo a ordenar las evidencias y construir las categorías de análisis, también a generar comprensiones sobre sus modos de construir sus saberes docentes, la cual fue un gran aporte al momento de reconstruir sus historias de vida. 
A continuación comparto por qué opté la metodología de historias de vida y, sin exponerlas como resultado, señalo de qué manera sus características más significativas -como la subjetividad, el vínculo investigador-investigado, la reflexividad y su potencial transformador- fueron aspectos importantes a desarrollar en la investigación.

\section{Discusión sobre los aportes de las historias de vida y su importancia en este estudio}

Comienzo comentando que, si bien el enfoque de historias de vida estuvo abandonado a partir de 1930, fue retomado en los 70 como una forma de rescatar la subjetividad en las investigaciones sociales (Munro, 1998). Este aspecto, comprendido como una de sus mayores fortalezas y entradas a la posmodernidad (Geiger, 1989), me acercó fuertemente a este enfoque por diversas razones.

Primero porque me ha mostrado que los estudios de historias de vida son una oportunidad para explorar la vida singular de las personas -en este caso mujeresenfocándose principalmente en sus relatos y experiencias subjetivas (Munro, 1998; Smith, 2012). Además permite, desde las propias palabras, comprender cómo los efectos de las estructuras sociales influyen en nuestras vidas y cómo lidiamos con esas estructuras de poder para dar sentido a la realidad.

Así, por ejemplo, recalco cómo para María José -una de las colaboradoras- fue relevante narrarse desde las propias palabras y recuerdos. "iEs que claro! señalaba- es diferente pensarse....y todo influye, la sensación que evoca ese recuerdo, el cómo tu lo dices y expresas...qué imagen se te viene a la cabeza, qué palabras ocupas...eh...el lenguaje dice más cosas que las que uno cree...y fue bonito pensar qué palabras ocupaba para contarte mi historia..."

Además, me acerqué a este enfoque ya que valoro la importancia que atribuye a la relación entre entrevistador y entrevistado. Esta perspectiva busca eliminar la distancia entre ambos (Goodson 2001, 2004; Smith, 2012) y concibe a los procesos de entrevistas, observaciones y construcciones de las historias de vida, como un proyecto que se desarrolla colaborativamente.

El centro de investigación con historias de vida no es meramente la transcripción literal de lo que dice una persona. La base de nuestro trabajo es la relación con la persona. Como investigadores, una de las facetas de nuestra capacidad de investigación debe ser el de mostrar un sentido de cuidado y preocupación para entender "posibilidad de otro". . . nuestros esfuerzos de investigación deben ser reformulados para que incluyan la capacidad de empatía. (Smith, 2012: 489 citando a Tierney, 1998:104-105)

Estos aspectos resuenan directamente en mi caso de estudio ya que, como investigadora, abrirme a la experiencia narrada de otras mujeres, que al igual que yo son artistas y docentes, implicó posicionarme desde la escucha y empatía como un sentido de experiencia compartida que estructuró la investigación.

Así lo comentaba otra de las colaboradoras, quien, en la última entrevista mencionó: "Creo que tú investigación tiene un gran valor y ha sido, primero, que das la confianza para que uno se abra, hable y se exponga...”. Desde este comentario, lo que intento explicar es la importancia que, esta perspectiva de estudio, da a las relaciones entre investigador y colaborador y, por ende, señalar que este vínculo no es un factor casual o anecdótico, sino primordial para desarrollar historias de vida, sobre todo si valoro 
que, desde el pensamiento de la diferencia sexual, es a partir del espacio entremujeres donde toma lugar privilegiado el hacer simbólico (Rivera, 2001).

Por otro lado, señalo la importancia de este enfoque como un método que permite estimular la reflexividad de las personas. Construir un saber sobre lo que significa enseñar es un proyecto abierto que nunca acaba, ya que como docentes siempre estamos aprendiendo sobre y desde nuestra práctica y también sobre y desde los otros. Ese conocimiento sobre cómo enseñar es re-construido todo el tiempo, a partir del proceso dinámico de reflexionar nuestras experiencias. Como señala Smith (2012), en el proceso de contar y narrar historias las y los individuos vamos reflexionando sobre nuestras identidades y relaciones con el mundo social. Así también lo expresaba Ángela, otra de las colaboradores del estudio, quien a su vez, en la última entrevista mencionó:

"Para mi fue [el proceso de entrevistas] como un mirarse al espejo, tiene mucho que ver con eso, con enfrentarse con una misma, porque son reflexiones que, por falta de tiempo, de darme el momento para mirarme a mí misma en lo que hago y en lo que soy, no hago. Pensar por qué hago esto, dónde surge toda esta idea de mí trabajo ha sido una reflexión muy profunda y completa..."

Así también, esta metodología permite, como señalaba la colaboradora anterior, que durante el proceso de hablar y conversar, tanto con nosotros mismos como con otros, podamos generar un diálogo y espacio reflexivo. Escuchar a otros y ser escuchados implica compartir experiencias, y hacer de la experiencia de escucha una instancia reflexiva para aprender sobre nuestras prácticas. Como plantea Richert (1992: 195), "escucharse unos a otros y ser escuchado abre muchas puertas para el docente que está aislado en una estructura escolar que prohíbe el intercambio de ideas". Desde aquí que la conversación con otros es esencial para construir conocimiento sobre nuestros procesos de enseñanza y aprendizaje. Generar un espacio de escucha e instancia de reflexión conjunta, permitió -en mi estudio- revisar de manera compleja y crítica sus experiencias de tránsito entre las artes y la educación.

En este sentido, las instancias de escucha compartida, en mi estudio, tuvieron un lugar importante y no solo fue relevante dar espacio a que cada una pudiera relatarse de manera individual en las entrevistas personales, sino también, y como plantea Richert (1992), de manera colectiva, como lo llevamos acabo en los dos focus group con las cuatro profesoras. Así lo comparte Valentina, una de las colaboradoras, quien, al finalizar el primer focus group, expresa:

"Yo tenía ganas de conocerlas a ustedes [refiere a las otras tres profesoras del estudio] porque como el proceso con Rosario, desde el blog y las entrevistas, ha sido algo que a mí me ha servido mucho para reflexionar y es como que igual tenía curiosidad de saber de ustedes al leer sus cosas. Uno se cierra mucho al lugar donde trabaja, entonces mi experiencia de pedagogía es la que he tenido siempre en ese lugar y me resulta muy interesante escucharlas y también muy bonito ver que, claramente, a cada una le gusta lo que hace porque todas hicimos mención al punto de que enseñar exige comprender que la educación es una forma de intervención en el mundo..."

Finalmente, y ligado al comentario anterior de Valentina, tomo el aporte de esta perspectiva como un espacio que permite generar experiencias transformadoras (Smith, 2012). Nos entrega la posibilidad para comprender los discursos sociales en los que estamos situados y bajo los que actuamos, y también para entender cómo generamos y articulamos nuestros propios discursos, decisiones y acciones. Esto también lo expresaba Victoria, la cuarta colaboradora de este estudio, quien me explicaba, desde sus palabras: 
"Para mi ha sido super enriquecedor, porque ha sido una especie de terapia artística expresaba mientras se reía- porque de pronto tenía todo como medio mezclado, entonces al ir verbalizando y al ir poniendo esto en este triangulo que tú mencionas mujer-artista-docente, uno como que va esclareciendo un poco los distintos roles. Este tomar conciencia, a través de los diversos diálogos...eh...me permitió armarme mejor...y claro...precisamente...entenderme y tomar conciencia. Con estas conversaciones he podido distanciarme y, a su vez, aclararme..."

Lo que esta experiencia de Victoria tiene de transformadora, toma relación con lo que ella y las otras tres colaboradoras -en otras instancias- han expresado sobre este "permitirse armarse mejor", como una posibilidad de hacer simbólico a través de narrarse. Esto, como posibilidad de significarse -dentro del pensamiento de la diferencia sexual-se llama el partir de sí, como una práctica que reconoce el valor de la experiencia personal y pone en juego el propio deseo de ser y estar en el mundo (Rivera, 1997).

\section{Conclusiones}

En este escrito he compartido la importancia de la metodología narrativa, como una perspectiva de investigación cualitativa que otorga espacio y valor a nuestros relatos como evidencias de estudio. Para ello, he compartido las características que considero de mayor importancia para construir historias de vida. Con ello, intento expresar que realizar esta metodología no implica simplemente recolectar datos o biografías para luego reconstruir historias ajenas, sino que -a parte de la importancia que implica un análisis denso, profundo y riguroso de dichos relatos- la etapa de recolección de relatos es un proceso de encuentro con el otro $u$ otra investigada, que nos invita a empaparnos de sus historias y vidas de manera relacional (Smith, 2012).

Por ello, presentar estos cuatro aspectos -la subjetividad, el vínculo investigadorinvestigado, la reflexividad y su potencial transformador- es una manera de repensar esta metodología y cómo contribuye a que podamos realizar investigaciones más cercanas a las realidades de los colaboradores.

Por último, reconstruir las historias de vida de las cuatro maestras ha permitido visibilizar, no sólo experiencias marginadas y silenciadas de mujeres, sino vivencias que han sido, además, poco valoradas e investigadas dentro de las disciplinas artísticas y de la educación en Chile. Por otro lado, reconstruir sus saberes, como historias de vida, es una forma de revalorar sus experiencias como mujeres y, por ende, un aspecto relevante sobre este proceso ha sido tomar en cuenta que, sus experiencias, tienen puntos en común y también de divergencia. Develar estas historias son aportes para generar mayores comprensiones sociales, sobre cómo las mujeres se resisten a los significados impuestos e interactúan dinámicamente para construir sus saber profesional (Munro, 1998).

\section{Referencias}

Bolívar, A. (2002). “¿De nobis ipsis silemus?”: Epistemología de la investigación biográfico-narrativa en educación. Revista Electrónica de Investigación Educativa, 4(1), 1-26.

Bolívar, Antonio \& Domingo, Jesús (2006). La investigación biográfica y narrativa en lberoamérica: Campos de desarrollo y estado actual. Forum: Qualitative Social Research, Sozialforschung, 7(4), Art. 12. <http://nbnresolving.de/urn:nbn:de:0114-fqs0604125> 
Bruner, J (1990). Acts of Meaning. Londres: Harvard University Press.

Bruner, $\begin{gathered}\text { J. } \\ \text { http://ewasteschools.pbworks.com/f/Bruner J LifeAsNarrative.pdf }\end{gathered}$ (2004). Life $\quad$ as $\quad$ Narrative.

Charmaz, K. (2006). Constructing grounded theory: a practical guide through qualitative analysis. London: Sage.

Clandinin, J. \& Connelly, M. (1990). Stories of experience and Narrative Inquiry. Educational Researcher, 19(5), 2-14.

Clandinin, J. \& Connelly, M. (1994). Teachers telling stories. Teacher Education Quarterly, 21(1), 145-158.

Clandinin, J., \& Connelly, M. (1995). Cap.1: Relatos de experiencia e investigación narrativa. En Larrosa (Ed.) Déjame que te cuente. Ensayos sobre narrativa y educación. (11-59) Barcelona: Laertes.

Clandinin, J. \& Connelly, M. (2000). Narrative inquiry: experience and story in qualitative research. California: JosseyBass.

Geiger, S. (1986). Women's Lifes Histories: Method and Context. Chicago Journals, 11(2), 334-351.

Goodson, I. (2001). The Story of Life History: Origins of the Life History Method in Sociology. Identity: An International Journal of Theory and Research, 1(2), 129-142.

Goodson, I. (2004). Historias de Vida del Profesorado. Barcelona: Octaedro.

Munro, P. (1998). Subjetc to Fiction. Women Teachers 'Life History Narratives and the Cultural Politics of Resistance. Philadelphia: Open University Press.

Richert, A. (1992). Cap. 12: Voice and Power in Teaching and Learning to Teach. En Valli, L. (Ed.) Reflective Teacher Educator. Cases and Critics. (187-197) New York: University of New York Press.

Rivera, M. (1997). El fraude de la igualdad. Barcelona: Planeta.

Rivera, M. (2001). Mujeres en relación: feminismo 1970-2000. Barcelona: Icaria.

Smith, J. (2012). Reflections on using life history to investigate women teachers' and career decisions. Qualitative Research, 12(4), 486-503. http://qri.sagepub.com/content/12/4/486.abstract

Van Manen, M. (2003). Investigación educativa y experiencia vivida. Barcelona: Idea Books. 